\title{
EFL: REVISITING ELT PRACTICES IN INDONESIA
}

\author{
Fernandita Gusweni Jayanti and Maida Norahmi \\ Universitas Negeri Malang \\ fernandita.gusweni@yahoo.com
}

\begin{abstract}
In the last decades, we have witnessed a revolutionary spread of English worldwide. This global spread of English can be attributed to the combination of various historical, political, economic, cultural, and technological factors. This led to the emergence of new varieties of English, multiple linguistic and cultural identities. However, for decades, the Western paradigm of English language teaching has occupied a prestigious position in Asia, including Indonesia. This paradigm neglects the emerging varieties of English. Furthermore, it is important to recognize that language teaching and learning is affected by a host of factors ranging from the macro political and cultural environments of a country or region to the micro perceptions and practices of individual teachers or learners, which calls for different methodologies for different learners or learning situations. This article attempts to discuss briefly the current issues in English language teaching (ELT) in Indonesia from English as lingua franca (ELF) perspectives, particularly by taking a close look at all the local features and limitations in the established theories and practices in ELT in Indonesia.
\end{abstract}

Keywords: English language teaching, contextual, methodology, EFL

As English becomes the language for international communication, more people use English for various purposes. Probably between two and three billion people speak English (Ur, 2009). English is used for academic purposes, tourism, entertainment, business and finance, information, political, interpersonal relationships and many other international purposes. Thus, having the ability to communicate in English becomes crucial. Crystal (2003) estimated that only about a quarter of the 1.5 billion or so people who speak English are native speakers, while the rest are those who speak English as a second language and foreign language. It is often claimed that around 80 per cent of the world's communication in English is among non-native speakers using the language with each other as a lingua franca rather than with native speakers. As a lingua franca, English is a "contact" language, lingual medium communication, between people of different mother tongues and culture (Firth, 1996).

People in the expanding circle use English for international communication and English occupies the dominant role in education system and a means of international communication (Sharma, 2008). He later adds that the people in the Expanding Circle usually do not use English for day to day purpose in local community but to communicate with people across nations and culture. This global spread of English and its emerging dominant roles have brought challenges in teaching and learning of English.

For decades, English language teaching (ELT) professionals in Indonesia have embraced the paradigm of teaching developed in Western countries. The traditional practices in Indonesia employ memorization and form-focused 
instruction which are proven by some studies to be ineffective (Wang \& Hill, 2011). It is apparent, however, that English is used for different purposes in various contexts across speakers in different places. Most, if not all, of the students learning English in schools in non-English-speaking countries will need that language is not in order to interact within a specific English speech community, but rather to communicate with other English speakers (some native but probably most non-native), both intra- and internationally (Ur, 2010). Furthermore, language teaching is affected by a host of factors ranging from the macro political and cultural environments of a country or region to the micro perceptions and practices of individual learners and teachers. All these considerations lead us to take a more realistic look at "what" is being taught and learned, "where" the teaching and learning is taking place, and "who" is involved in the teaching and learning. Furthermore, Nero (2006) indicates the need to reconceptualize ELT, and the need to reexamine the curricula, methodology, textbooks, materials, and expertise in ELT.

Current ELT Trends in Indonesia

With the emergence of today's role of English as an international language (EIL) and as a global lingua franca (ELF), it is hardly surprising that English language education has become important in many countries. The majority of Indonesian view English as a door to better employment and higher social status. This is what is called as instrumentalist point of view towards the global spread of English (Pan, 2011). In addition, English was seen as a requirement imposed by the globalization era. Without English, they believe that people in Indonesia would be left behind and unable to compete internationally. Thus, this belief triggers a growing number of schools range from kindergarten to university level in which English is used as the medium of instruction in Indonesia.

In Indonesia, English instruction begins in secondary (high) schools. According to 1967
Decree of the Ministry of Education and Culture (now known as the Department of National Education), the role of English in high schools was "to speed up national development in addition to establishing relationship with other nations and to carrying out its national foreign policy". Therefore, English is compulsory subject for these two levels. It is also one of the subjects that students have to take in their final examinations. Prior 1994, English was not compulsory at elementary level (primary school). Only after 1994 revised curriculum, Ministry of Education then has allowed elementary schools to include English as a subject for students of grade four, five, and six.

\section{Native-Speakerness Orientation}

The ELT practices in the classrooms in Indonesia reflect the natural tendency to set the goal towards the native-speaker norms. The choice of "native-speakerness" often falls into American or British English. Teachers become so ambitious to explicitly explain all the rules, drill the "standard" pronunciation, give samples of conversation from those native speakers and then give prompts to make the students speak like those speakers and exhaustingly correct the non-standard forms of students' production. They hold the belief that the students should have near-native proficiency and accuracy in order to be able to successfully and effectively engage in communication. Then, the students are forced to achieve that expectation.

In his survey, Zacharias (2003) reveals that many teachers in Indonesia a notable preference for materials from English-speaking countries, in particular for teaching pronunciation and listening skill, while not many of them had tried out locally-produced materials, towards which there was a certain degree of distrust. In particular, a number of respondents described locally-produced materials as inaccurate and incomplete. Indonesian teachers also acknowledge themselves as poor proficient teachers if they use mother tongue in their teaching. The majority of respondents in the study also expressed the 
belief that English language teaching should be accompanied by the teaching of the culture(s) of English-speaking countries, many of them found it useful to relate such cultural content to the students' culture.

Teachersseemnot aware with the unprecedented spread of English in which students have greater ability to meet non-native English speakers than to meet native English speakers from the inner circle countries. They tend to neglect the context of English use in Indonesia which is one of the expanding countries that use English to communicate globally in agreed standard of intelligibility among non-native speakers. What should be remembered that not many of English speakers from expanding circle can be experienced of being in native countries (Kirkpatrick, 2007). Hence, the expectations of being native-like and learning the culture(s) of English-speaking countries are no longer in primary needs.

\section{Problems Concerning the Attainability of Native-Speakerness}

With regard to the elusive nature of native speaker norms, ELT in Indonesia as EFL context have to consider issues concerning the attainability of native speaker norms. Lee (2005) asserts that to be justified as a native speaker, one has to have a command of "appropriate use of idiomatic expressions," "correctness of language form," " natural pronunciation," "cultural context ... including response cries ..., swear words, and interjections," "above average sized vocabulary, collocations and other phraseological items," "metaphors," "frozen syntax, such as binomials or bi-verbials," and "nonverbal cultural features". To conclude, he states that "it is impossible for any learner of a language, to become a native speaker unless he or she is born again".

It is also worth noticing that there is still a severe lack of learning resources and qualified English language teachers in Indonesia. We also have to acknowledge that most of Indonesian students are few obvious signs of the future use of the English language for purposes. They want to learn English because they think that it will be useful in getting a good job, which shows the instrumental function of English in Indonesia. The students also believe that the knowledge of two languages will make them a better educated person, which is related to the interpersonal function. For Indonesian learners who seem to learn English for instrumental purposes as a tool to utilize in cross-cultural settings, the need to learn the native speaker culture seems quite old fashioned.

\section{Contextual Factors in ELT}

There are three contextual factors will discussed to invite the reconstruction of recent ELT practice in EFL countries, especially in Indonesia.

\section{Different Roles of English}

Regarding the use of English, it is supposed to be different among the speakers with many sorts of background and environment. Referring to Kachru's "three-circles" model (1985) in which there are inner, outer and expanding circle, the emergence of global English in use is reshaped by the nature of nations and societies in each circle. This distinction divides countries in Asia into two distinctive circles, outer and inner circle (Wang \& Hill, 2011). According to Kirkpatrick (2007), the role of English will be treated differently distinction between English as a native language (ENL), English as a second language (ESL) and English as a foreign language (EFL). ESL and EFL tend to have the need of English communicative interaction as the results of global spread of English. Based on both major classifications, it should be needed to classify the role of English in different interests.

In ENL context, English is treated as the language is primary used in daily communication, education, official functions, and regards as the first language of people living in such countries. The norms of using English commonly used in global context of English are derived from this context. For the use in ESL context, role of 
English is regarded as one of the languages for official and education purposes. Also, English is the language used besides of people's mother tongue. The speakers living in this context tend to use English frequently since they are slowly moving on to ENL context. They are predicted to have more chances to stay in native-speaker countries (Alptekin, 2010). It is signaled by the acceptance of varieties in English they speak. The role of English is seen differently from those two contexts concerning EFL context. In this case, English is commonly served as a tool for supporting international communication. The English speakers in EFL context are commonly asked to follow the norms used by ENL speakers to be accepted in intelligible interaction.

In Indonesia which is one of expanding countries and serves English as a foreign language (EFL), the practice of ELT can be concluded using exonerative model in which the norms and standards of native speakers is put in priority. This is in line with Kirkpatrick (2007) stating that almost all of the expanding circle countries use native-speaker model in teaching English. It can be seen that the students are required to use the language in that way of native speakers as the standards of correctness. However, in Indonesia, English is only taught at schools and rarely use for daily communication. The main use of English is a tool for communicating internationally. Since the students are multilingual, the norms labeled as native-like should be reconsidered in the practice of ELT. In the case of multilingualism, there is great opportunity for English to be used among non-native speakers with different mother tongue to communicate (Wang \& Hill, 2011). Therefore, supposing English as a lingua franca tend to be more beneficial due to its flexibility in the diversity of mother tongue and cultural background.

\section{Contents/Materials}

In most expanding countries, the materials used in the practice of English teaching refer to textbooks published by ENL countries.
It comes as the result of having native-like competence as the ultimate goal of learning English. Relating to materials evaluation, one of the textbook evaluation criteria adapted from Robinett (1978) in Brown (2007) deals with the varieties of English and the existence of cultural bias. It means that the issue related to cultural content in materials should be taken into material developers. The monoculture (e.g. native speakers' cultural content) in such materials used to teach English is supposed to be no longer maintained. This is what will happen when the local cultures where English is taught are acknowledged.

Cultural content in ELT materials is still in debate. In expanding countries, the culture of native speakers seems to be forced to teach for the students with the respect of engagement with native speaking community. This is such of reasonable expectation since there are limited natural exposures in interacting with native speakers. However, this expectation is not always in line with the needs of global English and communicative purposes of the students (Kilickaya, 2004). What can be suggested is that teachers in EFL context are required to be more aware to such issue. They should be the ones who are responsible to make decision on the selection of cultural content for ELT classrooms based on their students' needs and cultural values.

English represents the culture of English native speakers, in contrast, the language is primarily taught in social and cultural contexts different from that of native speakers (Cahyono, 2013). This distinction in the contents of English materials leads to the proposal of facilitating multicultural contents in such materials. Then, many questions have then risen concerning what cultures should be involved in ELT practice outside the inner circle regarding the context of ESL and EFL. Pointing on this problem, according to Cortazzi \& Jin in McKay (2002), there are three kinds of cultural information should be involved in the selection or construction language textbooks or materials in non-native 
countries, those are, source culture, target culture, and international target culture.

From the above discussion, it is clearly seen that the monoculture in English teaching materials should be reconsidered for the sake of students' needs and purposes. Viewing from Indonesian context, this reconsideration tends to be in line with the endorsement of the Law Number 22/1999. This Law gives flexibility to have language policies relevant on local characteristics to provide relevant materials for Indonesian students. According to Cahyono (2013), this regulation helps to facilitate local culture contents for the teaching EFL in Indonesian context. Many local cultures in Indonesia can be acknowledged by other communities which do not have such cultures, for example religious ceremonies, folktales, courtesy, and politeness.

\section{Cultural Values}

As what has been discussed above, the English role and the contents of English teaching materials contribute differently in different settings. It has been stated implicitly that teaching the language is accompanied by teaching the culture of people using that language indirectly. Relating to this assumption, the main problem then comes on the rejection of western culture brought by English language in some parts of area. For example, in China, few times ago teaching and learning English concept is refused by great numbers of people stating that the language brings colonial values inside (Pan, 2011). Fortunately, this issue is now slow down because of the spread of global English. However, there are still many people who stand strongly in their cultural values reject the teaching of English. Their perception is lead by the 'negative values' of English based on historical background as colonial language. Moreover, not few of people still regard English to contain "alien values" (Kirkpatrick, 2007).

Indonesia consists of numerous cultures different from native speaker culture. This complexity in culture should be taken into account for the practice of ELT in Indonesia. Since the expectation of learning English is remarkably directed to native-like competence, the standard culture used in teaching English is the standard culture of native speakers. It seems to be confronting perspectives between the students' nature of cultural background and the expectation, if the multicultural values of students and the non-native speakers have not been acknowledge by language education practitioners, especially language teachers. Like Kirkpatrick's statement (2007), several countries do not use native speaker model any longer in order to block unwanted values and cultures inside the language. It is also suggested that English should be treated as a communication media facilitating the cultures of the speakers, not only native ones, using that language for communicating globally (Alptekin, 2010). That is why different cultural values should be inserted into English language use to avoid authority and the existence of dominant culture in the language. Therefore, the preciseness of English as representative of western culture should be excluded in ELT practice in nonnative countries.

\section{Bringing ELF Approach in ELT in Indonesia}

This is not the place to present a full theory of ELF. Interested readers can consult the exhaustive discussions in Jenkins (2006), Seidlhofer (2004) and McKay (2002). For our purposes, it should suffice to say that ELF refers to the (mainly spoken) English used in communication among the so-called 'non-native' users of the language. This does not, however, mean that native speakers are excluded, but the language they speak does not necessary provide the model for what is right and wrong (Powell, 2011). Kachru categories English speakers into three concentric circles (inner, outer, and expanding) in which each circle represents different type of English users. In the inner circle the native speakers of English are found, i.e. speakers of English who have English as their one and only 
mother tongue, e.g. Americans, Australians, Canadians and the British etc. The outer circle includes speakers of English who are second language speakers of

English, i.e. speakers who do not have English as their first language but who use English in every day communication. Thirdly there is the expanding circle whose members are people who use English as 'another language', i.e. people who have learnt English as a foreign language. Indonesian learners of English belong to the expanding circle.

In ELF view, speakers of ELF are not expected to produce utterances as similar as possible to the native speakers', but rather utterances that do not deviate too far from the utterances of the native speakers (Kirkpatrick, 2007). That is to say intelligibility is more important than native-like accuracy, which means that for example some pronunciation problems are regarded unnecessary to rectify as they do not disrupt intelligibility.

Studies on ELF interactions find that the salient characteristics of ELF use is the high level of cooperation and mutual support among speakers. In support to this, Seidlhofer (2004) points out some generalizations about the pragmatics of ELF. First, the ELF speakers employ overt negotiation by using communication strategies such as rephrasing and repetition to avoid misunderstanding. Therefore, misunderstandings are not frequent in ELF interactions even though they have different lingua-cultural background. ELF speakers tend to have no expectations regarding norms which makes interference from L1 interactional norms is very rare. Lastly, as long as a certain threshold of understanding is obtained, interlocutors seem to adopt what Firth (1996) has termed the "let-it-pass principle," which gives the impression of ELF talk being overtly consensus-oriented, cooperative and mutually supportive, and thus fairly robust. In this regard, it will not come as a surprise that interlocutors' cultural background and shared knowledge (or lack thereof) have been found to be important factors in ELF conversations since
ELF is a context or purpose use (Seidholfer, 2004).

One of the major discussions centers on the choice between native-speaker (NS) or non-native-speaker model. Ur (2010) identifies some considerations to provide learners with a practicable and appropriate model. First, facts show that the native-speakers are the minority of English speakers world-wide. Then, native speakers speak varieties of English which may not be acceptable outside the community. It is also worth to consider that majority of teachers who teach English for students that use English as lingua franca are non-native English teachers and they are often the only role-models that readily available for the students. It is also true in Indonesia. It is difficult for the schools to facilitate the students with NS models. Indonesia consists of thousands islands with many schools located in rural area and are underprivileged schools. Furthermore, serving NS as model will lead the learner to failure since becoming a native speaker seems like utopia. At last, we have to acknowledge that there is an increasing number of ELF users who were not originally native speakers of one of the varieties of English are today fully competent speakers of English, speaking and writing a correct, fluent and easily comprehensible variety of the language which is a totally acceptable model for learners.

Ur (2010) later suggests that it is not necessary to define whether such model is or is not originally a "native speaker". It is not the "native-speakerness" of the model speaker but it is simply the level of proficiency. Canagarajah (1999) then points out that local non-native teachers are the ones who know the expectations, beliefs, capabilities and assumptions of local learners and they are more aware of the importance of developing a curriculum matching with the learning culture in the community. Thus, the non-native English teachers should not feel inferior.

Moreover, we have to acknowledge that in ELF use, English is used for effective communication across linguistic and cultural boundaries. Thus, the focus of the classroom moves from the 
acquisition of standard native-speaker norms to a focus on learning linguistic features, cultural information and communicative strategies in different contexts of usage (Kirkpatrick, 2007). By adopting this approach, students will be exposed to many varieties of English including the native varieties.

ELF approach also accommodates variability of cultural conventions and pragmatic norms (Kirkpatrick, 2007). Acknowledging ELF use, teachers can promote the cultural values in their local context as well as cultural values of other ELF speakers across the different nations. ELF facilitates various cultures owned by various English speakers. The cultural contents can also be inserted in the materials used for English teaching. Due to greater sensitivity and awareness towards different cultural values and contents taken in learning English, the speakers can accept the diversity among English speakers. As Alptekin (2010) mentions that second language users are not only required having bilingualism - related attributes but also acquaintance with the knowledge owned by other cultures.

In EFL setting, it means that the speakers have to take into account the language use, social setting in which it is used and the speakers are suggested to be dynamic to tackle the interlocutors' varieties and cultures. Such multicompetence is crucial in ELF communication to avoid miscommunication and to fill in the gap between the language users. Then English is not supposed to bring "alien" or "foreign" values and contents to the local context of nonnative speakers. English then can be owned by its speakers all over the world without limiting its authority and norms only on native speakers' context. In eastern cultures, "face-work" seems to be important before making request to achieve standard of politeness in such cultures. ELF speakers must be sensitive with such cultural differences in order to communicate effectively with other speakers coming from various lingua-cultural backgrounds. Therefore, English become acceptable in wider different societies to enhance the functions of English language in global communication.

The context of teaching and learning English in Indonesia, where English has been used as a lingua franca or international language, should adopt the goals of a lingua franca approach. The approach has been initiated by Kirkpatrick (2007) who contends that a lingua franca approach based on the goal of successful cross-cultural communication could be advantageous to both teachers and students. Therefore, a curriculum should be adapted or adopted to match the reality of the context. Kirkpatrick (2007) suggests a curriculum which would include at least three strands:

1. Students would need to be alerted to which linguistic features cause particular problems of mutual intelligibility.

2. The curriculum would need to focus on how cultures differ and the implications of such differences for cross-cultural communication.

3. Students would need to be taught the communicative strategies that aid successful cross-cultural communication.

\section{CONCLUSION}

Dealing with English globalization, being able to communicate in that language is seen to be crucial in international competition. The needs and demands of English cannot be ignored anymore. Inevitably, every country over the world competes each other to have their people master English well. English then is taught as a school subjects and become the requirements to have bargaining job position. It is no wonder that the recent practices of ELT are put into major concern by linguists, pedagogical practitioners, education experts, and language policy makers, especially in countries outside the inner circle. Due to different setting of ELT practices, the standard norms and correctness related to "native-speakerness" is coming to be compromised. This proposal concerns facilitating non-native speakers' needs of the language without ignoring their multiculturalism. 
To conclude this discussion, ELT practices in Indonesia specifically and other expanding countries generally need to be revisited. Since there are still many language teachers over the world expect their students to be in native-like proficiency, an approach or model to press this "exaggerated" expectation into negotiable level is needed. Kirkpatrick (2007) in his book entitled World Englishes proposes lingua franca approach to serve English to be more neural in its use. By using this approach, the

\section{REFERENCES}

Alptekin, C. (2010). Redefining Multicompetence for Bilingualism and ELF. International Journal of Applied Linguistics, 20 (1).

Brown, H.D. (2007). Teaching by Principles: An Interactive Approach to Language Pedagogy ( $3^{\text {rd }}$ ed.). White Plains, NY: Pearson.

Cahyono, B.Y. (2013). Teaching English by Using Culture Contents. Malang: State University of Malang Press.

Canagarajah, A.S. (1999). Resisting Linguistic Imperialism in English Teaching. Oxford: Oxford University.

Crystal, D. (2003). English as a Global Language (2 ${ }^{\text {nd }}$ ed). Cambridge: Cambridge University Press.

Firth, A. (1996). The Discursive Accomplishment of Normality: On 'Lingua Franca' English and Conversational Analysis. Journal of Pragmatics, 26, 237-259.

Hill, C. \& Wang, H. (2011). A Paradigm Shift for English Language Teaching in Asia: From Imposition to Accommodation. The Journal of Asia TEFL, 8 (4), 205-232.

Jenkins, J. (2006). Current Perspectives on Teaching World Englishes and English as a Lingua Franca. TESOL Quarterly, 40 (1), 157-181.

Kilickaya, F. 2004. Guidelines to Evaluate Cultural Content in Textbooks. The Internet TESL Journal, 10 (12). issues of cultural values and contents can be inserted into teaching materials addressing local, target and international cultures. It is also open the language teachers mind to tolerate their students' imperfection in achieving the standard of native-like correctness. Another implication is that to reduce the pressure to speak and behave like native speakers. Finally, it is an attempt to acknowledge the cultural and social background diversity among non-native speakers who use English as a tool for international communication and competition.

Kirkpatrick, A. (2007). World Englishes: Implications for International Communication and English Language Teaching. Cambridge: Cambridge University Press.

Lee, J.J. (2005). The Native Speaker: An Achievable Model? Asian EFL Journal, 7 (2), 152163.

McKay, S. (2002). Teaching English as an International Language: Rethinking Goals and Approaches. Oxford: Oxford University Press.

Nero, S. (Ed.). (2006). Dialects, Englishes, Creoles, and Education. New Jersey: Lawrence Erlbaum.

Pan, L. (2011). English Language Ideologies (ELI) in Olympic Beijing. Applied Linguistics Review, 2, 75-98.

Powell, J. (2010). EFL vs ELF. Unpublished Thesis. Gothenburg: University of Gothenburg Department of Languages and Literatures English.

Seidlhofer, B. (2004). Research Perspectives on Teaching English as a Lingua Franca. Annual Review of Applied Linguistics, 24, 209-239.

Sharma, B.K. (2008). World Englishes, English as a Lingua Franca, and English Pedagogy. Journal of NELTA, 13 (1), 121-130.

Ur, P. (2009). English as a Lingua Franca and Some Implications for English Teachers. 
TESOL France Colloquium. Retrieved on May 8, 2013 from www.tesol-france.org/ Colloquium09/Ur_Plenary_Handouts. pdf

Ur, P. (2010). English as a Lingua Franca: A Teacher's Perspective. Retrieved on May 8, 2013 from www.letras.ufrj. br/anglo_germanicas/.../122010/.../ cl301220100penny.pdf

Wang, H. \& Hill, C. (2011). A Paradigm Shift for English Language Teaching in Asia: From Imposition to Accommodation. The Journal of ASIA TEFL, 8 (4), 205-230.

Zacharias, N.T. (2003). A Survey of Tertiary Teachers' Beliefs about English Language Teaching in Indonesia with Regard to the Role of English as Global Language. MA-ELT Thesis. Institute for English Language Education. Assumption University of Thailand. 
